\title{
Congenital Portosystemic Shunts in Children: Recognition, Evaluation, and Management
}

\author{
O. Bernard, MD, PhD ${ }^{1} \quad$ S. Franchi-Abella, MD $\quad$ S. Branchereau, MD ${ }^{3}$ D. Pariente, MD ${ }^{2}$ \\ F. Gauthier, $\mathrm{MD}^{3} \quad$ E. Jacquemin, $\mathrm{MD}, \mathrm{PhD}^{1}$
}

${ }^{1}$ Hépatologie pédiatrique, Hôpital Bicêtre, AP-HP, Université Paris-Sud,
Le Kremlin-Bicêtre, France
2 Radiologie pédiatrique, Hôpital Bicêtre, AP-HP, Université Paris-Sud,
Le Kremlin-Bicêtre, France
${ }^{3}$ Chirurgie pédiatrique, Hôpital Bicêtre, AP-HP, Université Paris-Sud, Le
Kremlin-Bicêtre, France

Address for correspondence and reprint requests Emmanuel Jacquemin, MD, PhD, Hépatologie Pédiatrique, Hôpital Bioêtre, AP-HP, Université Paris-Sud, 78 rue du Général Leclerc, Le Kremlin Bicêtre, France 94275 (e-mail: emmanuel.jacquemin@bct.aphp.fr).

Semin Liver Dis 2012;32:273-287.

\begin{abstract}
Keywords

- portosystemic shunts

- children

- liver tumors

- hepatopulmonary syndrome

- pulmonary hypertension

Congenital portosystemic shunts are present in one in 30,000 children. Among the associated risks of severe complications are neonatal cholestasis, benign and malignant liver tumors, hepatopulmonary syndrome, portopulmonary hypertension, and encephalopathy. They can be detected on prenatal ultrasonograms, during the investigation of a positive galactosemia screening test in neonates or of a complication, or be found fortuitously on an abdominal ultrasound. Small intrahepatic shunts may resolve spontaneously within one year of age, but other shunts such as extrahepatic, persistent ductus venosus or persisting intrahepatic shunts, must be closed in one or two steps, by interventional radiology techniques or surgically. The plasticity of the intrahepatic portal system allows revascularization of the liver after shunt closure, even when no intrahepatic portal structures can be detected on imaging studies. This leaves little or no place for liver transplantation in the management of these children.
\end{abstract}

The development of the liver results from epithelial and mesenchymal interactions connected to a network of early embryonic and then fetal vessels, some of which later involute both inside and outside the liver ${ }^{1}$; the ductus venosus, the last vessel to involute, normally disappears after a few days in term neonates, and after a few weeks in premature babies. ${ }^{2}$ The lack of complete involution of one or several of these primordial vessels may give rise to abnormal vascular communications between any vein of the portal system and any vein of the inferior vena cava system; these communications may exist inside or outside the liver, may be single or multiple, and vary in size. They can cause partial or complete diversion of the portal blood to the systemic vessel and carry risks of complications. They differ from the acquired intraand extrahepatic portosystemic shunts occurring as a consequence of portal hypertension. Over the past 30 years, there has been an exponential increase in the number of children with congenital portosystemic shunts (CPSSs) reported in the English language literature (-Fig. 1). The present review is based on the study of 265 such children aged 16 years or less

Issue Theme Pediatric Liver Diseases; Guest Editor, Joel E. Lavine, MD, PhD

at the time of the first symptoms or diagnosis: 250 children reported in the literature between 1979 and early $2012^{3-140}$, and 15 who were investigated at the Bicêtre Hospital since our publication of 22 patients in $2010 .^{118}$

\section{Anatomy}

It has been customary to classify CPSS into two categories, extrahepatic and intrahepatic, respectively. Extrahepatic shunts often called "Abernethy malformations" are further classified into types 1 and 2 depending on the patency (type 2) or apparent lack of patency of the portal trunk and intrahepatic portal system. ${ }^{21,28}$ The type 1 extrahepatic CPSS, sometimes called "congenital absence of the portal vein," was thought to require liver transplantation for a cure, ${ }^{47,86,87,128}$ whereas type 2 extrahepatic CPSS was amenable to closure, surgically or by interventional radiology procedures. ${ }^{132}$ On the other hand, intrahepatic CPSSs are located inside the liver and were classified into four categories. ${ }^{141}$ Although useful to some extent, these classifications

Copyright @ 2012 by Thieme Medical Publishers, Inc., 333 Seventh Avenue, New York, NY 10001, USA.

Tel: +1(212) 584-4662.
DOI http://dx.doi.org/ 10.1055/s-0032-1329896. ISSN 0272-8087. 


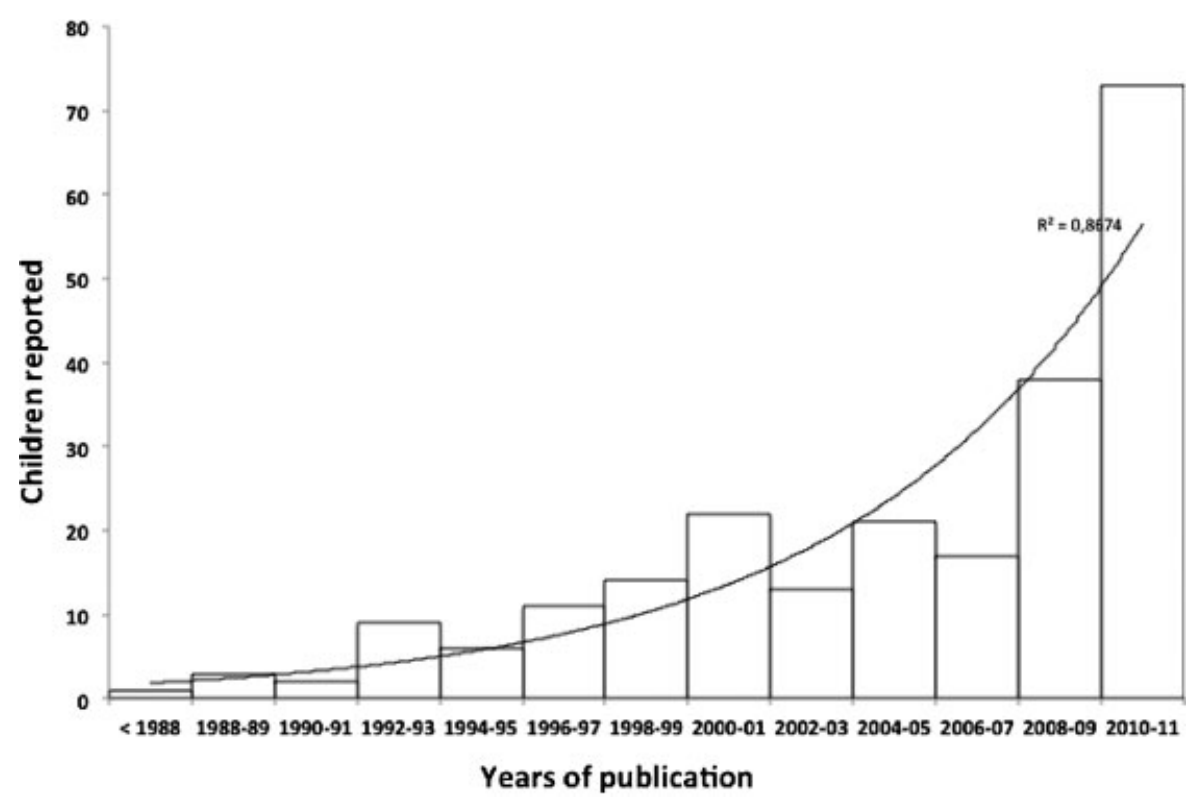

Figure 1 Number of children with a congenital portosystemic shunt reported in the English-language literature from 1979 to 2011.

are no longer fully valid for several reasons: (1) intra- and extrahepatic shunts carry the same risks of complications; (2) the intrahepatic classification was described mostly in adult patients with cirrhosis and may not be adapted to CPSSs in children; (3) the classifications do not take into account the persistence of the ductus venosus, a significant type of CPSS that cannot fit into an intra- or extrahepatic category; (4) there have been reports in which both extra- and intrahepatic shunts were present in the same child ${ }^{57,110,118}$; and (5) as far as extrahepatic shunts are concerned, assessment of the patency of the portal trunk and of its intrahepatic branches may give different results depending on the imaging technique $29,70,123,136 ;$ (6) successful portal revascularization of the liver has been reported after closure of the shunt in children in whom no portal vein had been seen, either during surgical examination or on an angiogram during an occlusion test, thus clearly showing the plasticity of the intrahepatic portal system. ${ }^{44,76,118}$ Consequently, the term "congenital absence of the portal vein" is misleading. Based on the results of imaging studies, we suggest that the PSSs be classified anatomically, taking the following into account: the part of the portal system where the shunt originates, including the afferent veins of the portal trunk (e.g., the splenic or superior mesenteric vein), the portal trunk itself, or intrahepatic branches; the systemic vein of termination of the shunt and the ductus venosus; the type of communication with the systemic vein (end-to-side versus side-to-side); and the number of communications (single vs multiple). The respective anatomic types of CPSS reported in the pediatric literature are indicated in - Table $\mathbf{1}$.

\section{Liver Pathology}

The liver is usually small, and amounts to 45 to $65 \%$ of the estimated standard volume for age. ${ }^{54,134}$ In children with socalled congenital absence of the portal vein, direct examina- tion of the extrahepatic portal system during surgery or of the explanted liver at transplantation or autopsy, either did not show any portal venous structure or remnants $3,4,61,82,86,87,93,125$ or showed vestigial fibrous remnants of the portal trunk at the porta hepatis, ${ }^{7,8,67,129}$ and sometimes showed a patent portal bifurcation with a break after the emergence of the right and left portal branches ${ }^{58,90}$; this does not preclude the presence and plasticity of the intrahepatic portal system: A detailed study of the liver of a child with a type 1 Abernethy malformation reports the presence of small caliber portal veins in the large portal tracts although no portal vein was found in the hilum ${ }^{142}$; this explains why closure of the shunt may revascularize the intrahepatic portal system, possibly through a small portal cavernoma probably developed from the peribiliary plexus and without significant portal hypertension. ${ }^{118}$

Liver histology, described in 62 children, was reported as normal in 16 children, as a fatty liver with no or little portal fibrosis in six children, and as a pattern reminiscent of hepatoportal sclerosis in 40: Minimal or moderate portal fibrosis, absent or hypoplastic portal vein branches in the portal tracts, large arterial branches with sometimes a thickened wall, portal and periportal proliferation of thin vascular, capillary, or lymphatic structures, and in one instance, slight ductular proliferation. Perisinusoidal fibrosis or early-stage nodular regeneration was sometimes present. This pattern is similar to the one described in rats and is probably the consequence of portal blood deprivation. ${ }^{143}$

\section{Prevalence and Possible Mechanisms}

Two studies use the results of neonatal screening for galactosemia after a few days of feeding to estimate the prevalence of congenital portosystemic shunts ${ }^{144,145}$ : High concentrations of blood galactose, unexplained by an abnormal activity of the enzymes of galactose metabolism, can be found in neonates 


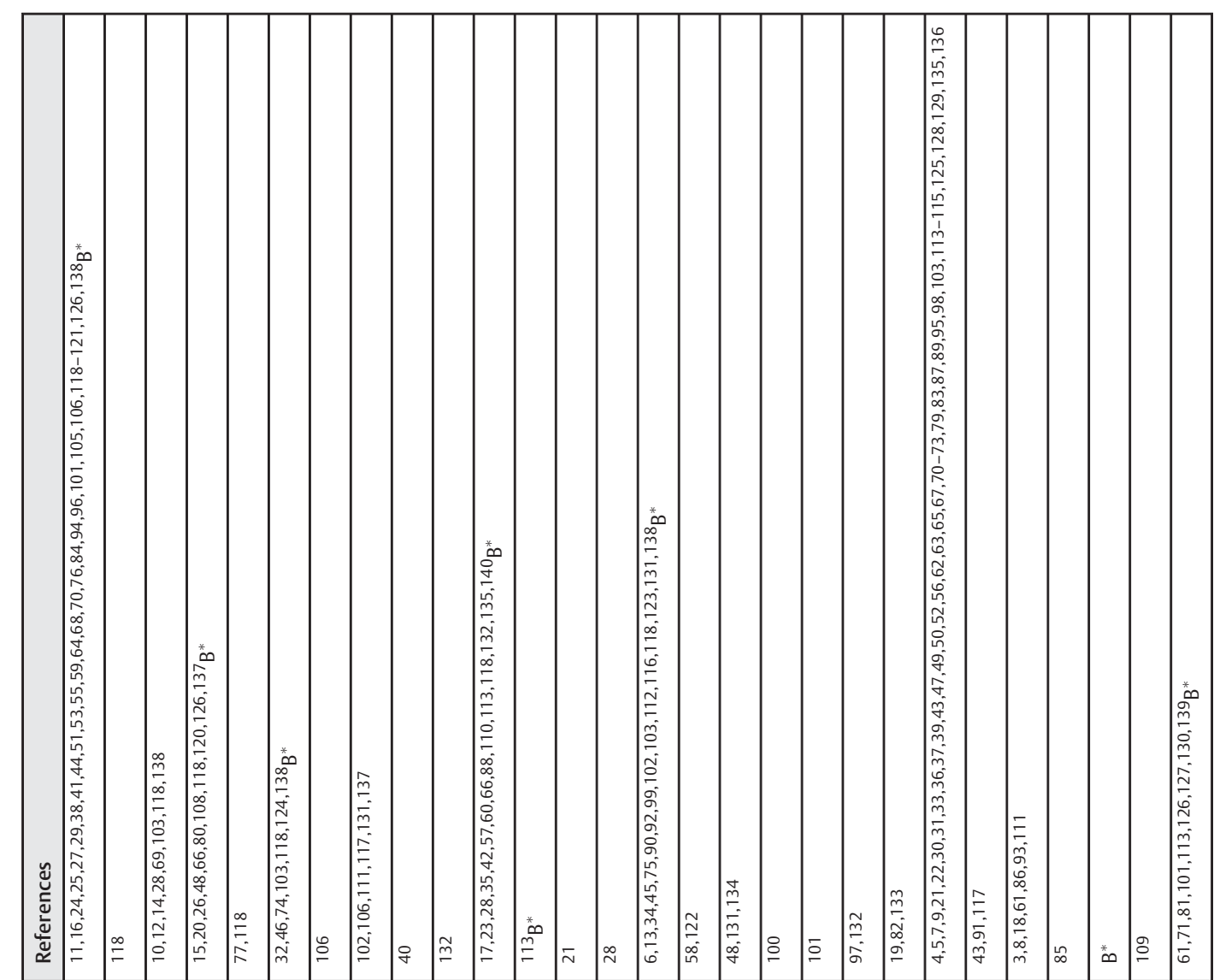

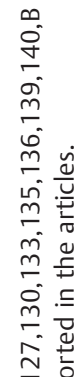

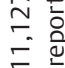

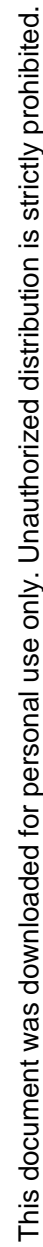

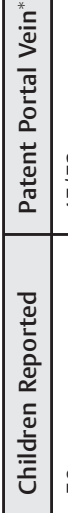

$\bar{n} \overbrace{}^{n}$

i. E

离

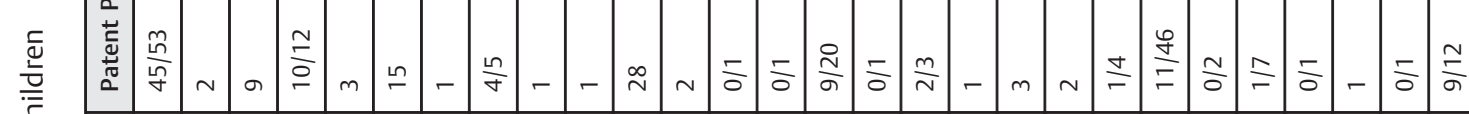

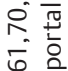

$\stackrel{\infty}{\stackrel{0}{*} .0}$

กิ

oi

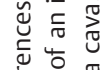

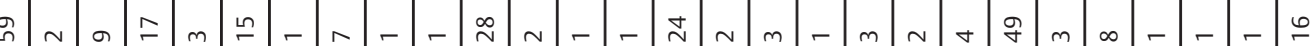

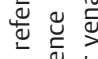

至

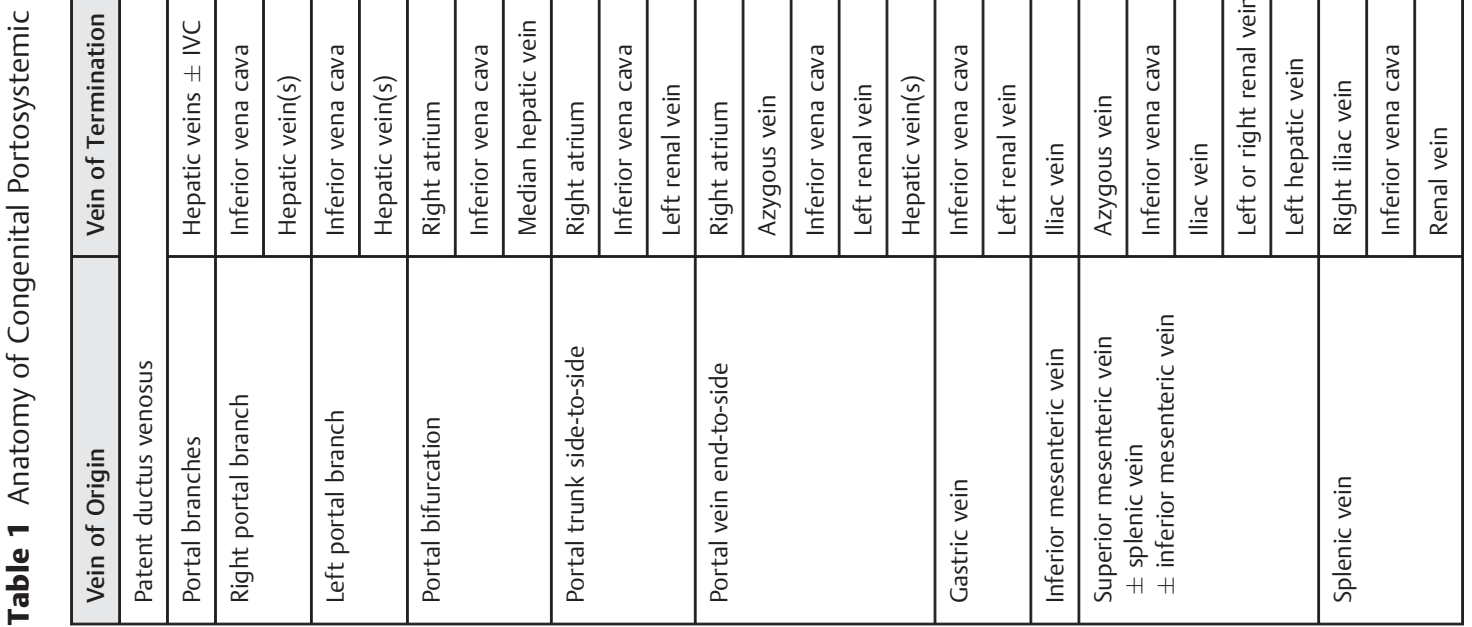

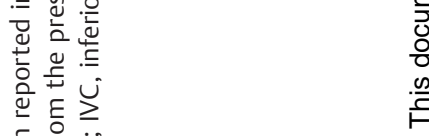


Table 2 Presenting Signs of Congenital Portosystemic Shunts in 265 Children

\begin{tabular}{|l|l|l|}
\hline Period of Time & Type of Finding & Number of Patients \\
\hline Prenatal (20-37 weeks) & Abnormal ultrasound & 27 \\
\hline \multirow{4}{*}{ Neonatal } & Total & 78 \\
\cline { 2 - 3 } & Abnormal galactosemia test & 55 \\
\cline { 2 - 3 } & Congenital heart disease & 12 \\
\cline { 2 - 3 } & Neonatal cholestasis & 10 \\
\cline { 2 - 3 } & Fortuitous & 1 \\
\hline \multirow{5}{*}{ After age 1 month } & Total & 160 \\
\cline { 2 - 3 } & Complication of shunt* & 117 \\
\cline { 2 - 3 } & Fortuitous imaging finding & 29 \\
\cline { 2 - 3 } & Abnormal liver test & 12 \\
\cline { 2 - 3 } & Not reported & 2 \\
\hline
\end{tabular}

*Including neonatal cholestasis, liver tumors, hepatopulmonary syndrome, pulmonary hypertension, encephalopathy, and others, see Outcome section.

with CPSS because galactose from milk bypasses the liver. The overall prevalence is close to 1:30,000 births and the prevalence of permanent CPSS can be estimated at 1:50,000. Possible clues to the understanding of the development of congenital portosystemic shunts include the following: (1) A genetic origin-of the 265 children who form the basis of this review, 11 had Down syndrome and 13 had another genetically defined disease or syndrome; all the anatomic types of shunts were found in these children. In addition a persistent ductus venosus was found in siblings in five families including three pairs of twins. ${ }^{27,84,94,96,119}$ (2) A complex congenital malformative process-various abnormalities of the kidneys, bile ducts (including biliary atresia), digestive system, bones, and brain have been recorded, but a congenital heart disease is the most frequent, as it was combined with a CPSS in 45 of the 265 studied, in most cases with shunts originating or ending outside the liver. ${ }^{37}$ A polysplenia syndrome with azygous continuation of the inferior vena cava was present in 23 children, all with CPSS originating and ending outside the liver; indeed a recent study of children with the polysplenia syndrome reports the presence of a CPSS in at least $8 \%$ of cases. $^{146}$ (3) The absence of ductus venosus during fetal life-occlusion or agenesis of the ductus venosus may be associated with the presence of abnormal vessels that allow the oxygenated blood from the umbilical vein to reach the fetal heart. Some of these vessels may persist, present as CPSS and may be combined with extreme hypoplasia of the portal venous system. ${ }^{147-149}$ In a few such children, the development of the CPSS was followed from the fetal to the postnatal stage. ${ }^{107,147}$ Absence of ductus venosus was in fact recorded in a few children reported for CPSS., $72,62,63,73,107,118$ (4) A hemangioma of the liver-intrahepatic communications between branches of the portal vein and hepatic veins may be present in liver hemangiomas in early infancy; a few of them may persist while the hemangiomas regress and may present as intrahepatic shunts later in life. ${ }^{68,118,134,145}$

\section{Clinical Presentation and Investigation}

Of the 265 children included in this review, their gender was reported in 255 cases; there were 113 girls and 142 boys. There was a female predominance in children with extrahepatic shunts, reported as type 1 Abernethy malformation (sex ratio: 0.57 ), and a male predominance in children with persistent ductus venosus (sex ratio: 2.6). Presenting symptoms are indicated in - Table 2.

At the time of diagnosis, besides the possible signs of associated conditions or complications, the liver was not reported to be enlarged; a large number of cutaneous angiomas were reported in 10 children. Splenomegaly was recorded in five children with no patent signs of portal hypertension, excluding the children with biliary atresia. Serum alanine aminotransferase activity was above normal in 48 of 115 children tested (median value: $1.5 \times N$; range $1.1-11 \times N$ ), serum $\gamma$-glutamyltransferase activity was above normal in 25 of 50 children reported (median value: $3 \times N$; range $1.5-$ $15 \times N$ ), prolonged prothrombin time was reported in 31 of 77 children tested, and the serum albumin concentration was below $35 \mathrm{~g} / \mathrm{L}$ in 14 of the 35 tested. High ammonemia was reported in 123 of 156 children (median: $2 \times \mathrm{N}$; range 1.1 $10 \times N$ ), and high total serum bile acid concentration in 76 of 78 children. Note that one of the two normal bile acids values was recorded in a child with polysplenia syndrome before the Fontan operation, whose blood was flowing through the shunt from the systemic to the portal vein. ${ }^{81}$

Doppler ultrasonography (US) is the key imaging modality for the diagnosis, monitoring during the therapeutic procedure, and follow-up of CPSS (- Figs. 2, 3). In all types of CPSS, the portal and /or hepatic veins anatomy is modified and is the first obvious finding. Shunts joining a portal branch to a hepatic vein or the ductus venosus are easily diagnosed from the enlargement and in some cases tortuosity of both communicating vessels. The hypoplasia of the other portal 


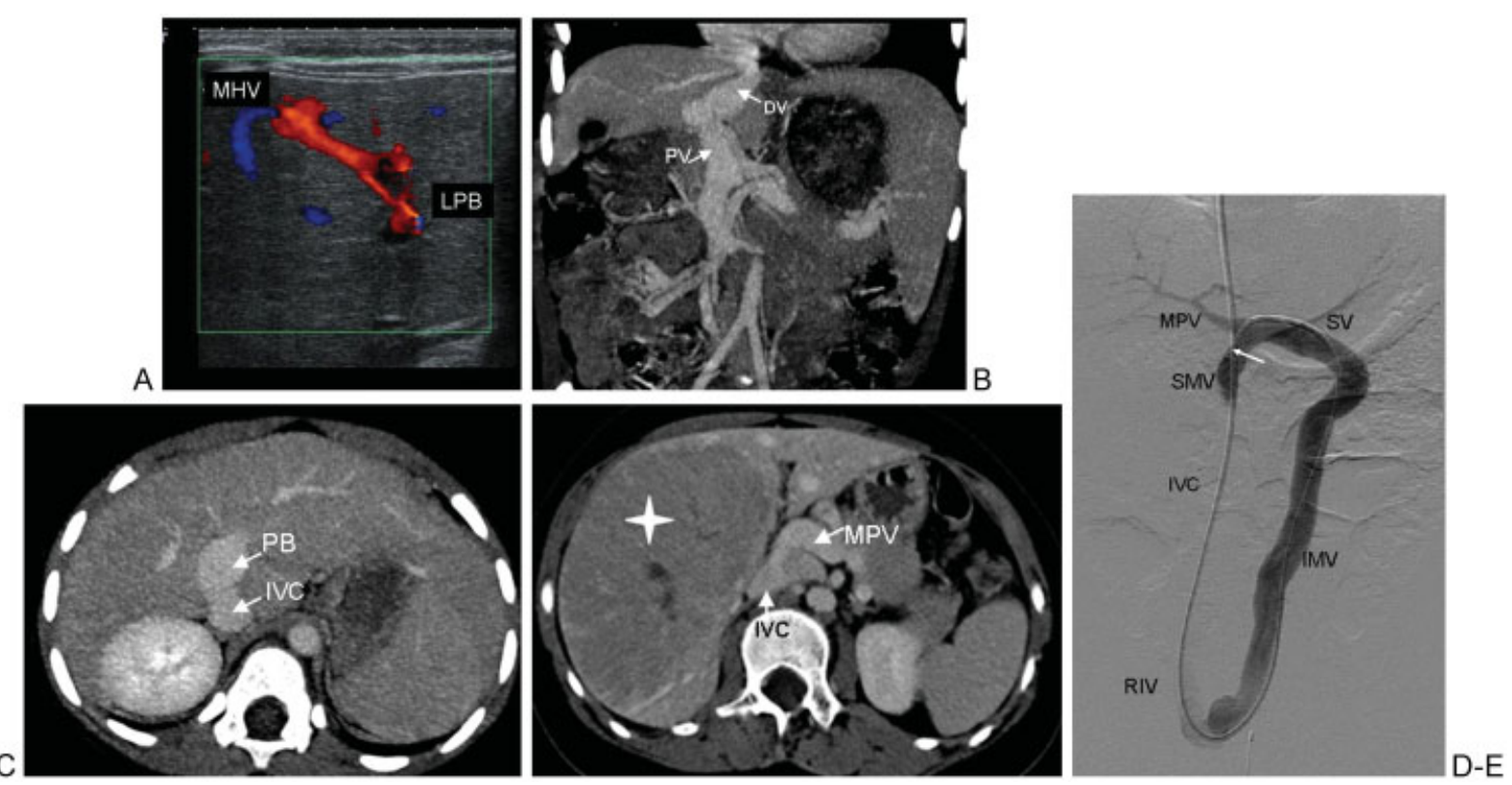

Figure 2 Imaging of various types of congenital portosystemic shunts in children: (A) Color Doppler shows a direct communication between a portal branch arising from the left portal branch (LPB) and a branch of the middle hepatic vein (MHV) in a one-month-old girl. Spontaneous regression was observed at one year of age. (B) Contrast-enhanced computed tomography (CT) with coronal reconstruction shows a patent ductus venosus (DV) joining the left portal branch and the inferior vena cava (IVC). Closure was performed surgically. (PV, portal vein) (C,D) CT with axial reconstruction shows: $(C)$ side-to-side communication between the portal bifurcation (PB) and the IVC. Note the dilatation of the PB;

(D) end-to-side communication between the origin of the main portal vein (MPV) and the IVC, below the liver. Both shunts were closed surgically. (E) Angiogram showing direct communication between the inferior mesenteric vein (IMV) and the right iliac vein (RIV). The catheter was inserted via a transjugular access and its tip (arrow) was placed into the SMV via the following pathway: IVC-RIV-IMV-splenic vein (SV)-SMV. The MPV and intrahepatic branches are well seen. Closure was performed by interventional radiology.

branches or their reversed flow is indicative of the size of the shunt. Compensatory dilatation of the hepatic artery may be misleading by indicating a more complex arteriovenous malformation, but the continuous venous flow in the communicating veins helps to reach the correct diagnosis. Shunts joining the main portal vein to the inferior vena cava, end-toside or side-to-side, may be more difficult to assess, as in most of the cases there is decreased liver size, sometimes with dysmorphy. The main finding is the nonvisibility of the intrahepatic portal branches that often appear as hyperechoic bands surrounded by hypoechoic stripes, thus giving the portal space a layered appearance (-Fig. 3). Portal flow may be slow or even absent, and arterial signal is the predominant recorded flow in the portal space. Side to-side shunts usually present with ectasia of the portal vein at the level of the shunt. Liver tumors may sometimes mask the causal CPSS. Shunts joining afferent branches of the portal vein (i.e., the splenic or mesenteric veins) to the infrahepatic inferior vena cava or its affluent (the renal or iliac vein) may also be difficult to detect by Doppler US, as they are far from the liver, and only the effect of the diversion of the portal flow to the portal vein and its branches and the hyperarterialization of the liver may be observed.

Multidetector computed tomography (CT) with contrast injection is the next imaging modality to perform, to further document the anatomy and location of the shunt (-Figs. 2,3). Together with maximum intensity projection and multiplanar reconstruction, it provides all the necessary information about the course of the shunt, its size, and orientation; it helps to define the best therapeutic option and access route for radiologists or surgeons. It is also useful for the detection of complicating liver tumors.

Magnetic resonance imaging (MRI) of the abdomen can also visualize the shunt, but is often less informative in small children than multidetector $\mathrm{CT}$ because of motion artifacts. However, its main indication is the evaluation of associated liver tumors, which present with variable signal intensity on T1- and T2-weighted images and variable contrast enhancement. Characterization of these lesions is difficult and biopsy is needed for diagnosis.

Angiography is performed either as an attempt to close the shunt percutaneously, or to detect the nonvisible portal vein and its intrahepatic branches and thus to provide arguments for closure in one step or more progressively in two steps. When portal branches are not visible on the initial opacification of the shunt, the occlusion test with a balloon occlusion catheter placed in the shunt, or in the inferior vena cava at the level of the shunt, is essential (-Fig. 3). It helps to calibrate the venous communication, which is always more distensible than is thought, and shows the presence and location of the portal vein and the degree of hypoplasia of the intrahepatic portal branches. Portal pressure measurement is recorded before and after occlusion to evaluate the tolerance of the closure of the shunt.

The results of tests of radiologic or surgical occlusion of the shunt were reported in the literature in 70 children, including measurement of portal pressure in 59 and angiography in 30 . Occlusion portal pressures were below $20 \mathrm{~mm} \mathrm{Hg}$ in 23 

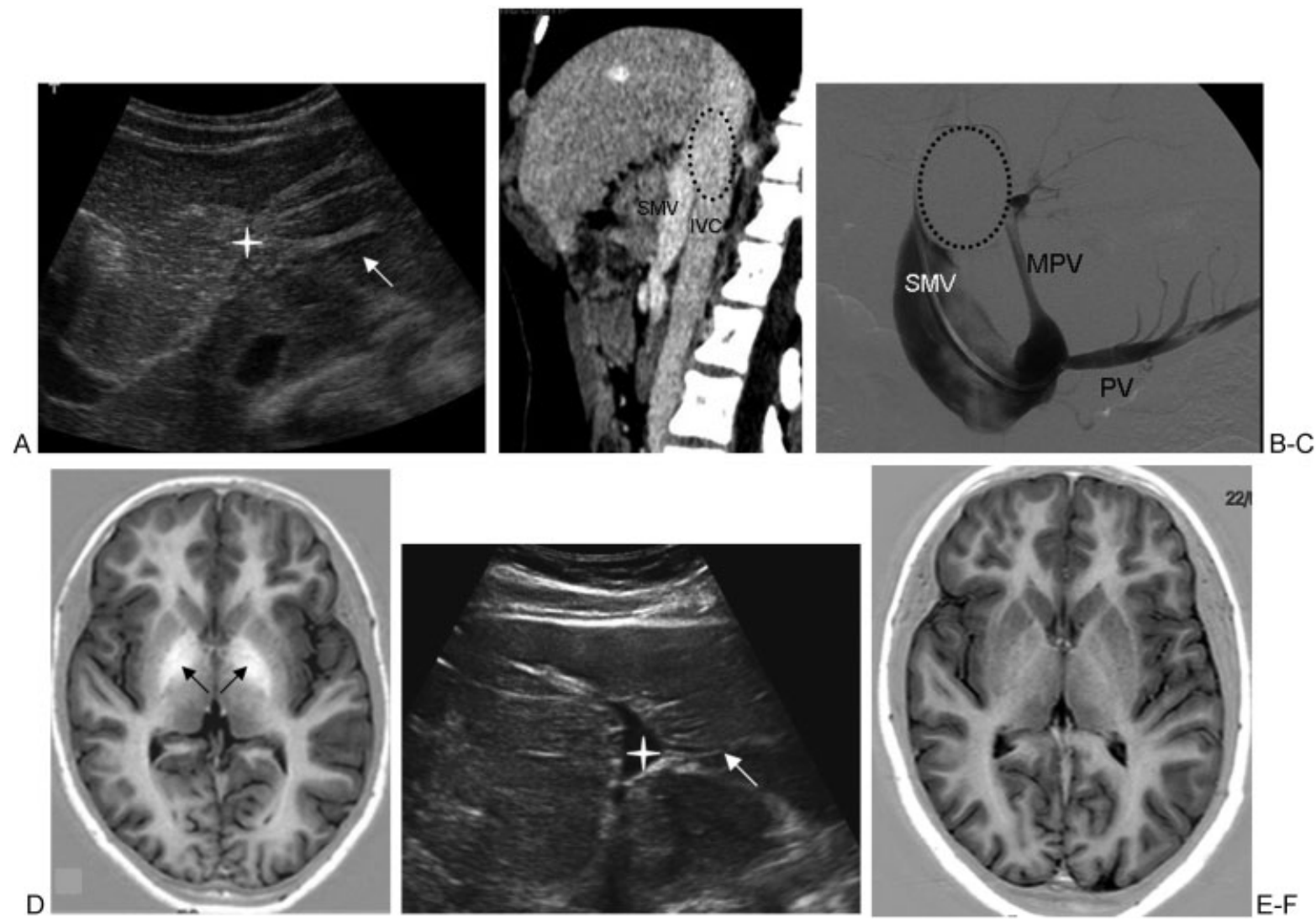

Figure 3 A 12-year-old girl presenting with encephalopathy and congenital portosystemic shunt. (A) Liver ultrasonography (US) shows the lack of visibility of the intrahepatic portal branches with a layered appearance of portal spaces consisting of hyperechoic bands surrounded by hypoechoic stripes (white arrow). Note that the lumen of the left portal branch is not seen (star). (B) Computed tomography with contrast injection and sagittal reconstruction shows direct end-to-side communication between the confluence of the superior mesenteric vein (SMV) and the splenic vein on one side and the inferior vena cava (IVC) on the other. The dotted circle shows the position of the balloon in the IVC during occlusion test. (C) Occlusion test with injection in the SMV reveals the unexpected presence of an ectopic main portal vein (MPV) arising from a pancreatic vein (PV) with hypoplastic intrahepatic portal branches. (D) Brain magnetic resonance imaging (MRI) performed before closure of the shunt shows on T1-weighted images a high signal intensity in the pallidi (arrows). Surgical closure of the shunt was performed in one step. (E) Three months later, US showed the patency of the left portal branch (star) and its branches (arrow). (F) One year later, brain MRI showed the disappearance of the abnormal high signal intensity in the pallidi (arrows). Dramatic clinical improvement of the girl's behavior occurred early after closure.

children, between 20 and 29 in 20 children and $30 \mathrm{~mm} \mathrm{Hg}$ or more (range 30-45) in 16. The increase in pressure was reported to be transient in three children, returning to values below $20 \mathrm{~mm} \mathrm{Hg}$ within a few minutes to an hour of occlusion. An intrahepatic portal system, often very hypoplastic, was seen on angiograms in 26 out of 30 children, including 10 out of 12 , whose occlusion portal pressure was between 30 and $45 \mathrm{~mm} \mathrm{Hg}$.

Per-rectal scintigraphy allows quantification of the shunt. ${ }^{150}$ The shunt ratios reported in the literature in 39 children range from 29 to $99 \%$ (median: 55\%); the shunt ratio is significantly related to the level of ammonemia ( $p=0.0009$; Student's $t$ test) and to the presence of clinical signs of encephalopathy ( $p=0.0062$; Fisher's exact test).

Brain MRI may reveal high signals of the globus pallidus bilaterally (- Fig. 3) and also of the antehypophysis on T1-weighted images and proton MR spectroscopy abnormalities have also been reported. High signals of the globus pallidus, initially described in adult patients with cirrhosis and portal systemic encephalopathy, ${ }^{151}$ were later related to the degree of portal systemic shunting rather than the degree of liver failure, ${ }^{152}$ and are thought to reflect the presence of manganese deposits in the basal ganglia. ${ }^{153}$ The results of brain MRI were reported in 42 children with various anatomic types of CPSS: High signals of the globus pallidus were found in 35 children aged 18 months to 18 years, could be seen in children with no clinical signs of encephalopathy, and were associated with high blood manganese concentrations. $33,54,111,154$

\section{Outcome}

Some small intrahepatic portosystemic shunts located between the portal branches and hepatic veins disappear spontaneously by age 1 to 2 years, ${ }^{155}$ but others, mostly the large shunts as well as the communications involving the extrahepatic portal veins and ductus venosus, persist throughout life and carry risks of complications. In the 


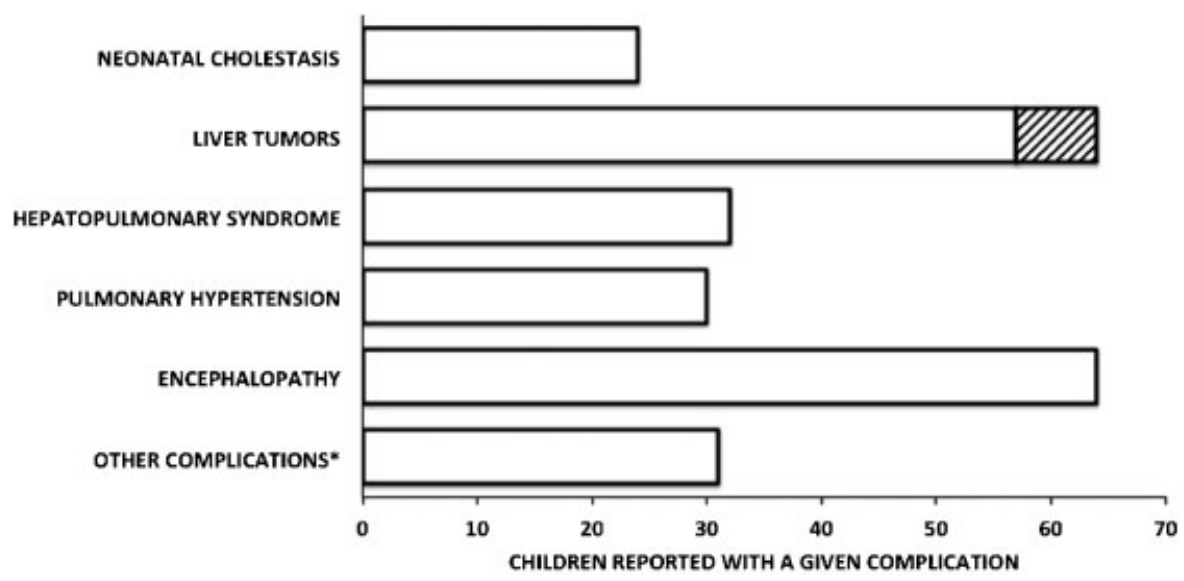

Figure 4 Two hundred forty-five complications reported in 182 children with a congenital portosystemic shunt. Fifty-one children presented with two simultaneous complications and six children with three complications. ${ }^{*}$ Including heart failure, membranoproliferative glomerulopathy, hypoglycemia, hyperandrogenism, acute or chronic pancreatitis, rectal bleeding, autoimmune disorders, protein-losing gastropathy, vaginal bleeding, fulminant liver failure, severe bleeding during surgery for scoliosis. Hatched bars: Malignant liver tumors.

population of children reviewed for this study, spontaneous shunt disappearance was observed in 14 children: In 12 of them, the shunt was located between an intrahepatic portal branch and a hepatic vein; in one, between the portal bifurcation and the inferior vena cava, and in one it was described as a persistent ductus venosus. ${ }^{138}$ Although an unknown proportion of CPSS may remain clinically silent for decades, ${ }^{156}$ many complications can occur in childhood (-Fig. 4).

\section{Neonatal Cholestasis}

Twenty-four infants reported to have a neonatal cholestasis of an unknown cause also presented with a CPSS; they included all the anatomic types. ${ }^{15,28,38,48,63,74,103,107,118,138}$ In 10 cases, the shunt was found during the investigation of jaundice; in the other 14 , it was identified by a galactosemia screening test, a prenatal ultrasonographic examination, or the investigation of a congenital heart disease. Intrauterine growth retardation was present in nine of 18 children whose birth weight and term were reported; premature birth was recorded in five of 19 children. Significant signs were thrombocytopenia in five children, prolonged prothrombin time despite parenteral vitamin K administration in eight children and lasting hypoglycemia in five of the eight in whom glycemia was reported. Stool discoloration was absent or transient in all six children in whom it was reported. Spontaneous resolution of jaundice occurred in 16 survivors. One may postulate that the presence of a shunt reduces the perfusion of the neonatal liver, a factor known to enhance the risk of cholestasis in neonates. The search for a shunt should be part of the investigation of a child with neonatal cholestasis, but its presence should not preclude the search for other causes of neonatal cholestasis, including biliary atresia, which is sometimes combined with a shunt, mostly with polysplenia, $, 21,28,48,61,102,103$ and respiratory chain disorders or adrenal insufficiency, which may present with hypoglycemia. In view of the good prognosis for this type of anoxoischemic cholestasis, early closure of the shunt is not necessary, but closure should be considered later if the shunt does not regress spontaneously.

\section{Liver Tumors}

Liver tumors have been reported in 64 children at a median age of 8 years (range 3 months-18 years). ${ }^{3-6,8,14,17,18,20,25,30,39,43,49,50,53,54,60,61,65,68,70,75,79,83}$ $85,89,90,92,93,103,109,114,118,123,124,128,132,134,135,137$ They were multiple in 38 children and single in 26 . Tumor histology was reported in 38 children and included adenoma in seven children, focal nodular hyperplasia in 16, and nodular regenerative hyperplasia or "regenerative nodules" in 11. Seven malignant tumors (hepatocellular carcinoma, hepatoblastoma, or sarcoma) $)^{3-6,17,61,93,118}$ were recorded, including two children in whom the malignant tumor occurred several years after the diagnosis of an adenoma or of a nodular regenerative hyperplasia., ${ }^{4,5,118}$ All anatomic types of CPSS were combined with liver tumors, but the malignant ones were combined with extrahepatic shunts. In 27 instances, the shunt was fortuitously diagnosed together with the tumor. The results of surgical or radiologic closure of the shunt without resection of the tumor were available for 21 children with a benign lesion (mean follow-up: 21/2 years; range 4 months-8 years): The disappearance or significant regression of the tumor was recorded in each case, even for very large tumors and for one patient in whom no portal vein was visible on the angiogram during an occlusion test. ${ }^{118}$ Whereas malignant tumors require resection, these results strongly suggest that closure of the shunt allows regression of benign tumors.

\section{Pulmonary Arteriovenous Shunting (Hepatopulmonary Syndrome)}

Chronic hypoxemia with clinical characteristics similar to those of hepatopulmonary syndrome has been reported in 32 children at ages ranging from 3 months to 11 years (mean:

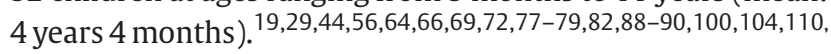
$112,115,118,123,127,128,133,135-137,139,140$ It was observed with 
all anatomic types of CPSS and led to the diagnosis of CPSS in 29 instances. Hepatopulmonary syndrome was a complication in 10 (none with biliary atresia) of the 23 children with CPSS and polysplenia syndrome and in 22 of the 242 children without polysplenia syndrome $(p<0.0001$; Fisher's exact test). Children with CPSS and polysplenia presented with hypoxemia at a younger age ( 3 months- 2 years; mean: 1 year) than children without polysplenia ( 1 year-11 years; mean: 51/2 years; $p<0.0001$, unpaired Student's $t$ test). Six of the children reported in the literature did not undergo any treatment; follow-up was available for three: One died of a brain abscess 6 months after diagnosis, one presented with pulmonary hypertension and is alive after a follow-up of 8 years, and one has stable hypoxemia after 1 year. Eight children underwent liver transplantation; follow-up is available for seven and shows full regression of hypoxemia 1 month to 1 year after transplantation. Nineteen children underwent surgical or radiologic closure of the CPSS in one or two steps: full regression of hypoxemia was observed in all but one child (range up to 10 years; mean: 2); in this child, pulmonary arteriography showed the persistence of pulmonary arteriovenous shunts that are considered to be associated arteriovenous malformations ${ }^{118}$; in another child, the emergence of additional portosystemic shunts was complicated by pulmonary hypertension 4 years after the regression of hypoxemia. ${ }^{78,110}$ These results indicate that CPSS may be present in children with unexplained hypoxemia and pulmonary arteriovenous shunting and that closure of the CPSS cures hypoxemia in virtually all cases, but requires careful follow-up. In addition, one must mention two reports of hepatopulmonary syndrome disclosing a previously unknown CPSS 8 months and 8 years, respectively, after liver transplantation for biliary atresia and the polysplenia syndrome. $^{136,157}$ Search for a congenital portosystemic shunt is recommended in children with biliary atresia, polysplenia and hepatopulmonary syndrome and closure of the shunt might be considered in lieu of transplantation whenever possible.

\section{Pulmonary Hypertension}

Pulmonary hypertension has been reported in 30 children at ages ranging from the neonatal period to 15 years (mean: 5 years 4 months) with all anatomic types of shunt. $^{24,35,42,50,51,58,61,99,101,107,109,110,114,118,127,129,130,133,138 ~}$

Signs of pulmonary hypertension were the occasion of the diagnosis of CPSS in 19 instances, and consisted of dyspnea, fainting, screening by clinical examination or echocardiography, or rapid right heart failure leading to death. The latter was observed in two children aged 12 and 20 months, who had extrahepatic shunts. ${ }^{58,130}$ There was a link between pulmonary hypertension and hepatopulmonary syndrome in five instances: in two children hepatopulmonary syndrome was followed by pulmonary hypertension after 3 to 4 years. In the other three children, the simultaneous presence of hepatopulmonary syndrome and pulmonary hypertension was reported, but the results of right heart catheterizations were not mentioned. Fifteen children fulfilled the criteria defined for portopulmonary hypertension ${ }^{158}$ : In two, postmortem study showed lesions of plexogenic pulmonary arteriopathy, ${ }^{58,130}$ and in 13 , the results of right heart catheterization showed elevated pulmonary resistances ranging from 5 to 38 wood units- $\mathrm{m}^{2}$ (median: 7). ${ }^{51,101,118,133}$ - Table 3 indicates the outcome for these children: Six children died and pulmonary arterial pressures and resistances did not return to normal values after treatment in survivors. These ominous results indicate that CPSS must be searched for in children who present with unexplained pulmonary hypertension, and that conversely, scrupulous care is mandatory in children with CPSS to detect the emergence of pulmonary hypertension early, even in very young children, to provide the child with the best chances of regression after early closure before the development of irreversible pulmonary vascular lesions.

\section{Encephalopathy}

Neurologic abnormalities were reported in 64 children with a CPSS, excluding patients with biliary atresia and portal systemic encephalopathy. $4,5,11,13,16,17,24,27,31,34,35,39,41,43,45$,

Table 3 Outcome of 15 Children with a Congenital Portosystemic Shunt Complicated by Pulmonary Hypertension Proven Either by Right Heart Catheterization Providing the Results of the Pulmonary Vascular Resistances (13 Children Aged 8 Months to 12 Years; Mdn: 7 Years) or by Postmortem Examination Showing Pulmonary Plexiform Arteriopathy at Ages 12 and 20 Months, Respectively

\begin{tabular}{|c|c|c|c|c|}
\hline \multirow{2}{*}{$\begin{array}{l}\text { Number } \\
\text { of Children }\end{array}$} & \multirow{2}{*}{$\begin{array}{l}\text { Pulmonary Vascular } \\
\text { Resistances (Wood u-m²) }\end{array}$} & \multirow[t]{2}{*}{ Treatment } & \multicolumn{2}{|c|}{ Outcome (Follow-Up) } \\
\hline & & & Alive & Dead \\
\hline 7 & 5-38 (Mdn: 7)* & None & $\begin{array}{l}2 \text { ( } 3 \text { Years) } \\
\text { Stable PP }\end{array}$ & 5 (0-12 Years) \\
\hline 2 & 6 & $\operatorname{Drug}(s)^{\dagger}$ & $\begin{array}{l}2 \text { ( } 1-5 \text { Years) } \\
\text { Stable PP }\end{array}$ & \\
\hline 1 & 8 & Liver transplantation & & $\begin{array}{l}1 \text { ( } 3 \text { Years) } \\
\text { Improved PP }\end{array}$ \\
\hline 5 & 5-26 (Mdn: 7) & Shunt closure $\pm \operatorname{drug}(s)^{\dagger}$ & $\begin{array}{l}5 \text { ( } 2-13 \text { years }) \\
\text { PP: Stable ( } 1 \mathrm{pt}) \text {, improved ( } 2 \text { pts), } \\
\text { impaired ( } 2 \text { pts) }\end{array}$ & \\
\hline
\end{tabular}

*Results in five children who underwent right heart catheterization.

†'lloprost, Bosentan, and/or Sildenafil.

MdN, Median; PP, pulmonary artery pressure; pt, patient. 
47,50,68,78,85-87,94,96,99,101,105,108,110,118,119,123-125,128,131,132, $135,136,138$ Because of the malformations, past medical histories and genetic syndromes sometimes associated with the CPSS, it is not always easy to attribute an abnormal neurologic sign to the possible consequence of portal systemic encephalopathy and/or to the brain toxicity of ammonia and manganese. The reported abnormalities can be divided into three main categories: (1) clear-cut signs of portal systemic encephalopathy, including intermittent episodes of lethargy or confusion after meals, or abnormal or bizarre behavior sometimes combined with irritability, agitation, or disorientation, slow waves on electroencephalograms (EEGs) and extrapyramidal signs on neurologic examination; (2) speech delay, mental retardation, sometimes combined with seizures; and (3) difficulties at school, behavioral problems and attention hyperactivity disorders in older children. The neurologic symptoms were observed at all ages, could be observed with all anatomic types of shunt and may be related to the magnitude of the shunt as measured by per-rectal scintigraphy (see above). Raised ammonemia was present in all but three children and high signal intensity in the globus pallidus on brain MRI was present in 15 of 18 children studied. Closure of the shunt or liver transplantation was performed in 46 children. Follow-up information was available for 28 children: Full regression of neurologic symptoms was observed in seven children, significant subjective improvement was noted by the parents in 18 , including one child whose seizures disappeared, and no modification was noted in three children. Ammonemia levels were normal in all 24 children tested after closure of the shunt. High signal intensity in the globus pallidus disappeared in all six children studied 3 months to 3 years (mean: 1 year 5 months) after shunt closure. These data suggest that abnormal neurologic symptoms or behavior, as well as school difficulties, especially when combined with high ammonemia, abnormal brain MRI, and improvement after closure of the shunt, could be the consequence of portal systemic encephalopathy and can be used as an argument for closure of the shunt.

\section{Other Complications}

Other complications have been reported in a few children that might be consequences of the CPSS: They include heart failure, $7,32,48,84,118$ membranoproliferative glomerulopathy, 45,118,131,135 hypoglycemia, 53,55,77,134 hyperandrogenism, ${ }^{43,52}$ pancreatitis, ${ }^{101}$ rectal or vaginal bleeding, ${ }^{43,67,105,132}$ autoimmune diseases, ${ }^{64,77,99,101}$ protein-losing gastropathy, ${ }^{35,132}$ unforeseen bleeding during surgery for scoliosis, ${ }^{117}$ and acute lethal liver failure during an episode of gastroenteritis in a 1.7-year-old boy with an extrahepatic shunt. ${ }^{54}$

Hypoxemia due to pulmonary arteriovenous shunting, pulmonary artery hypertension, encephalopathy with hyperammonemia, and glomerulopathy are known complications of cirrhosis, and their occurrence in children with congenital portosystemic shunts and minimal liver histologic lesions argues in support of the major role of communications between the portal blood and the systemic circulation in the origin of these conditions. The high incidence of liver tumors or nodules, whether benign or malignant, in children with congenital portosystemic shunts is reminiscent of what was described in some strains of rats ${ }^{159}$ and strengthens the concept of a portal deprivation syndrome in which abnormal portal venous flux results in the production of liver nodules of various kinds, as suggested to occur in patients with hepatoportal sclerosis, focal nodular hyperplasia, and focal regenerative hyperplasia, as well as in patients with portal vein obstruction after a surgical portosystemic shunt.

In all, with a follow-up ranging from 0 to 20 years, 19 of the 265 children included in this review died, nine possibly of causes unrelated to the CPSS and 10 of causes very likely to be the consequence of the shunts, one each of brain abscess with hepatopulmonary syndrome, hepatocellular carcinoma or acute liver failure, and seven children with pulmonary hypertension.

\section{Management}

Whenever a CPSS is found in a child, either during the investigation of a complication, during the neonatal period, or later as a fortuitous finding, one has first to make sure that the shunt is not the consequence of portal hypertension, or during early infancy, of a liver hemangioma that would require a specific treatment. Once the congenital and isolated nature of the shunt has been ascertained, the recommended investigations are indicated on - Table 4.

Table 4 Schematic Proposed Initial Investigation for a Child Presenting with a Congenital Portosystemic Shunt

\begin{tabular}{|l|}
\hline Blood Tests: \\
\hline Serum transaminases and $\mathrm{y}$-glutamyltransferase activities \\
\hline Coagulations studies \\
\hline Pre- and postprandial ammonemia and glycemia \\
\hline Fasting serum total bile acids concentration \\
\hline Blood manganese concentration \\
\hline Serum $\alpha$-fetoprotein concentration (in case of liver tumor) \\
\hline Imaging Studies: \\
\hline Abdominal Doppler color ultrasonography \\
\hline Multidetector CT and/or MRI with contrast injection \\
\hline Angiography of the shunts with or w/o occlusion test \\
\hline Echocardiography \\
\hline Brain MRI \\
\hline Per-rectal scintigraphy \\
\hline Others: \\
\hline Psychometric evaluation \\
\hline Percutaneous $\mathrm{O}_{2}$ saturation \\
\hline Proteinuria \\
\hline Liver histology (when indicated) \\
\hline Liver tumor histology (when indicated) \\
\hline
\end{tabular}

$\mathrm{CT}$, Computed tomography; MRI, magnetic resonance imaging. 
Because of the severity of its complications, closure of a congenital portosystemic shunt is necessary.

\section{Techniques for Closure}

As a general rule, percutaneous closure can be performed when an occlusive device can be fixed in position in the shunt, without compromising the development of the portal branches, the flow in the inferior vena cava and the normal hepatic veins and also the venous drainage of the other organs such as the spleen and kidneys. This therapeutic option applies to shunts between portal branches and hepatic veins that can be closed by means of Amplatzer devices or coils, depending on the size and number of communications. A patent ductus venosus can be successfully managed in this way, except when it is too wide or short to safely block the device in its lumen, in which case surgery must be undertaken. Shunts joining a splenic or mesenteric vein to an affluent of the inferior vena cava such as a renal vein or an iliac vein can also be easily closed percutaneously when they consist of endto-side communications. On the other hand, when the shunt is side-to-side, surgery is certainly preferable, at least in young children, to the placement of a covered stent in the lumen of the efferent vessel, as the latter option would require lifelong anticoagulation treatment and would probably become inadequate in size with growth. For the same reasons, side-to-side shunts between the main portal vein and the inferior vena cava are also indications for surgery, usually performed in one step. On the contrary, end-to-side shunts between the main portal vein and the inferior vena cava usually require a two-step surgical procedure to avoid acute severe portal hypertension.

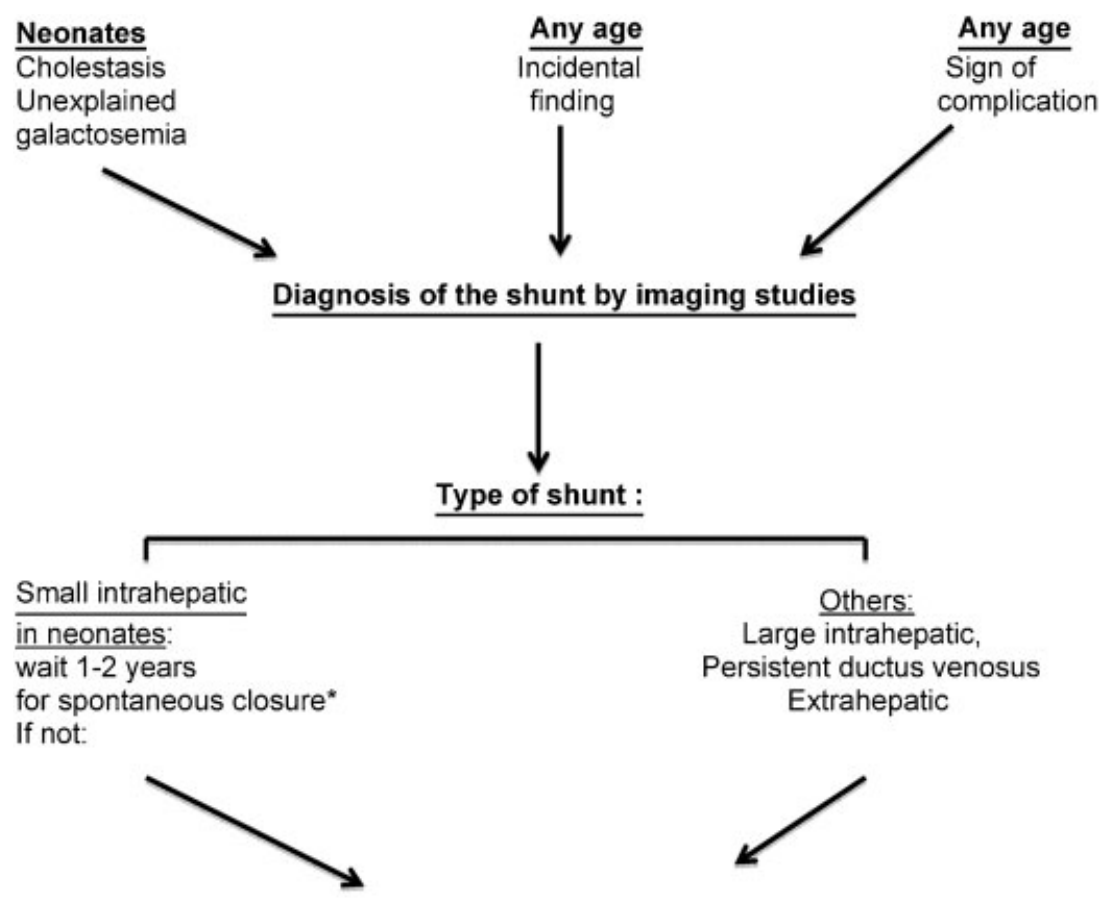

$\underline{\text { Consider shunt closure }}$

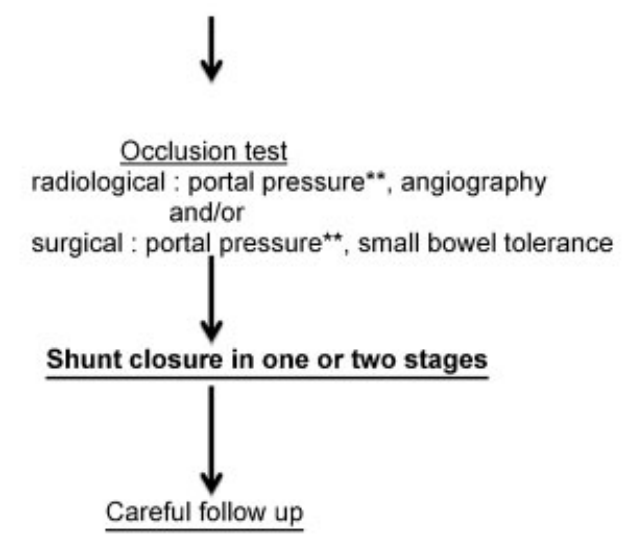

Figure 5 A schematic proposal for the management in a child with congenital portosystemic shunt. ( ${ }^{*}$ with the exception of an early complication, other than cholestasis, that requires closure of the shunt; ${ }^{* *}$ no precise cut-off value of occlusion portal pressure can be given to decide upon closure in one or two stages, but by and large, a stable occlusion portal pressure above $32 \mathrm{~mm} \mathrm{Hg}$ should lead to the consideration of a two-stage procedure, especially if no portal vein is visible on the occlusion angiogram. During surgery, the most important point is the tolerance of the small bowel during the occlusion (see text). 
The first step, consisting of banding of the shunt, allows the intrahepatic portal branches to progressively develop through a cavernomatous hepatopetal network. Complete closure a few months later can then be performed without significant portal hypertension. In complex forms of shunt, successive radiologic and surgical procedures are required to tailor the best therapeutic option for the closure of single or multiple shunts and finally to avoid liver transplantation.

Surgical closure of the shunt is indicated in patients considered unsuitable for endoluminal closure. The rules of this surgery are as follows: (1) The shunt must be occluded as close as possible to the caval system to preserve the maximal number of intrahepatic portal branches; (2) the occlusion must be checked to see that it does not result in excessive portal pressure and/or in small bowel cyanosis and edema; and (3) the thrombosis of blind portal segments must be prevented. The site of occlusion should be chosen after a careful multidisciplinary work-up. The details of the surgical approach (open, or rarely, laparoscopic, mobilization of liver, etc.) are planned according to the route of the shunt. Intraoperative monitoring of portal blood pressure during a 15-minute clamping test is strongly recommended. In case of good bowel tolerance, closure of the shunt may be achieved as a one-stage procedure by ligation, placement of clips or caval partition. In case of poor tolerance, a two-stage procedure is necessary, i.e., banding of the shunt followed by delayed closure after enlargement of intrahepatic portal vessels, sometimes after development of a portal network. ${ }^{34,44,118}$ Heparin is given before clamping and continued for one to several weeks, depending on the promptness of intrahepatic portal enlargement and on the possible formation of blood clots in blind segments. Shunt disappearance and development of intrahepatic portal branches are assessed by repeat Doppler US sonography, and by CT or MRI angiogram when necessary.

After closure of the shunt, the abnormalities shown by liver tests and coagulation studies regress. Ammonemia returns to normal within a day and serum bile acids are again normal after a few days. ${ }^{71,97}$ Careful follow-up is necessary for several years to check for the regression of complications when present, for long-term management of persistent complications such as pulmonary hypertension, and to detect the possible emergence of an additional shunt that would require additional closure ${ }^{108,118}$; the latter is best detected by a combination of abdominal ultrasonography and assay for serum bile acids concentration.

\section{Indications for Closure}

With the exception of neonatal cholestasis, which resolves spontaneously, closure of the shunt is mandatory whenever a complication is present (-Fig. 5) ${ }^{118}$ When no complication is detected, closure of the shunt can be postponed in cases of a small intrahepatic shunt (i.e., between a branch of the portal vein and a hepatic vein) found in early infancy because there is a reasonable hope of spontaneous shunt regression during the first year. In all other cases, closure of the shunt should be considered early, to prevent complications from occurring, for four reasons: (1) hepatopulmonary syndrome and pulmonary hypertension may be present during the very first years of life; (2) the regression of pulmonary hypertension cannot be ascertained once irreversible lesions of the pulmonary arteries are present; (3) chronic hyperammonemia and high blood levels of manganese have adverse effects on the developing brain ${ }^{160,161}$; and (4) the plasticity of the intrahepatic portal system may be better in younger children. ${ }^{121}$ The plasticity of the intrahepatic portal system will allow revascularization of the liver even when the intrahepatic portal system is not detectable on imaging studies and when portal pressure is high during an occlusion test. The experience gained over the past 15 years indicates that there is very little place left, if any, for liver transplantation in the management of congenital portosystemic shunts in children.

\section{References}

1 Collardeau-Frachon S, Scoazec JY. Vascular development and differentiation during human liver organogenesis. Anat Rec (Hoboken) 2008;291(6):614-627

2 Loberant N, Herskovits M, Barak M, et al. Closure of the ductus venosus in premature infants: findings on real-time gray-scale, color-flow Doppler, and duplex Doppler sonography. AJR Am J Roentgenol 1999;172(1):227-229

3 Marois D, van Heerden JA, Carpenter HA, Sheedy PF II. Congenital absence of the portal vein. Mayo Clin Proc 1979;54(1):55-59

4 Morse SS, Taylor KJ, Strauss EB, Ramirez E, Seashore JH. Congenital absence of the portal vein in oculoauriculovertebral dysplasia (Goldenhar syndrome). Pediatr Radiol 1986;16(5):437-439

5 Barton JW III, Keller MS. Liver transplantation for hepatoblastoma in a child with congenital absence of the portal vein. Pediatr Radiol 1989;20(1-2):113-114

6 Joyce AD, Howard ER. Rare congenital anomaly of the portal vein. Br J Surg 1988;75(10):1038-1039

7 Bellah RD, Hayek J, Teele RL. Anomalous portal venous connection to the suprahepatic vena cava: sonographic demonstration. Pediatr Radiol 1989;20(1-2):115-117

8 Nakasaki H, Tanaka Y, Ohta M, et al. Congenital absence of the portal vein. Ann Surg 1989;210(2):190-193

9 Woodle ES, Thistlethwaite JR, Emond JC, et al. Successful hepatic transplantation in congenital absence of recipient portal vein. Surgery 1990;107(4):475-479

10 Jabra AA, Taylor GA. Ultrasound diagnosis of congenital intrahepatic portosystemic venous shunt. Pediatr Radiol 1991;21(7): 529-530

11 Gitzelmann R, Arbenz UV, Willi UV. Hypergalactosaemia and portosystemic encephalopathy due to persistence of ductus venosus Arantii. Eur J Pediatr 1992;151(8):564-568

12 Kieran MW, Vekemans M, Robb LJ, Sinsky A, Outerbridge EW, Der Kaloustian VM. Portohepatic shunt in a Down syndrome patient with an interchange trisomy 47,XY,-2, + $\operatorname{der}(2),+\operatorname{der}(21) \mathrm{t}$ $(2 ; 21)(\mathrm{p} 13 ; q 22.1)$ mat. Am J Med Genet 1992;44(3):288-292

13 Kitagawa S, Gleason WA Jr, Northrup H, Middlebrook MR, Ueberschar E. Symptomatic hyperammonemia caused by a congenital portosystemic shunt. J Pediatr 1992;121(6):917-919

14 Lalonde L, Van Beers B, Trigaux JP, Delos M, Melange M, Pringot J. Focal nodular hyperplasia in association with spontaneous intrahepatic portosystemic venous shunt. Gastrointest Radiol 1992; 17(2):154-156

15 Lewis AM, Aquino NM. Congenital portohepatic vein fistula that resolved spontaneously in a neonate. AJR Am J Roentgenol 1992;159(4):837-838

16 Maisawa S, Takasago Y, Oyake Y, Maeta H, Fujiwara T. Patent ductus venosus with hypoplastic right hepatoportal system in a young child born with asymmetric intra-uterine growth retardation. Eur J Pediatr 1992;151(8):569-571 
17 Shah R, Ford E, Wooley M. Congenital portocaval shunt. Pediatr Surg Int 1992;7:216-217

18 Kamiya S, Taniguchi I, Yamamoto T, et al. Analysis of intestinal flora of a patient with congenital absence of the portal vein. FEMS Immunol Med Microbiol 1993;7(1):73-80

19 Papagiannis J, Kanter RJ, Effman EL, et al. Polysplenia with pulmonary arteriovenous malformations. Pediatr Cardiol 1993; 14(2):127-129

20 Kawakatsu M, Vilgrain V, Belghiti J, Flejou JF, Nahum H. Association of multiple liver cell adenomas with spontaneous intrahepatic portohepatic shunt. Abdom Imaging 1994;19(5):438440

21 Morgan G, Superina R. Congenital absence of the portal vein: two cases and a proposed classification system for portasystemic vascular anomalies. J Pediatr Surg 1994;29(9):1239-1241

22 Laverdiere JT, Laor T, Benacerraf B. Congenital absence of the portal vein: case report and MR demonstration. Pediatr Radiol 1995;25(1):52-53

23 Mboyo A, Lemouel A, Sohm O, et al. Congenital extra-hepatic portocaval shunt. Concerning a case of antenatal diagnosis. Eur J Pediatr Surg 1995;5(4):243-245

24 Yanai S, Minami T, Sonoda K, et al. Patent ductus venosus associated with a hyperintense globus pallidum on T1-weighted magnetic resonance imaging and pulmonary hypertension. Eur J Pediatr 1995;154(7):526-529

25 Matsubara T, Sumazaki R, Saitoh H, Imai H, Nakayama J, Takita H. Patent ductus venosus associated with tumor-like lesions of the liver in a young girl. J Pediatr Gastroenterol Nutr 1996;22(1): 107-111

26 Santamaría G, Pruna X, Serres X, Inaraja L, Zuasnabar A, Castellote A. Congenital intrahepatic portosystemic venous shunt: sonographic and magnetic resonance imaging. Eur Radiol 1996; 6(1):76-78

27 Uchino T, Endo F, Ikeda S, Shiraki K, Sera Y, Matsuda I. Three brothers with progressive hepatic dysfunction and severe hepatic steatosis due to a patent ductus venosus. Gastroenterology 1996;110(6):1964-1968

28 Howard ER, Davenport M. Congenital extrahepatic portocaval shunts-the Abernethy malformation. J Pediatr Surg 1997;32(3): 494-497

29 Orii T, Ohkohchi N, Kato H, et al. Liver transplantation for severe hypoxemia caused by patent ductus venosus. J Pediatr Surg 1997;32(12):1795-1797

30 Guariso G, Fiorio S, Altavilla G, et al. Congenital absence of the portal vein associated with focal nodular hyperplasia of the liver and cystic dysplasia of the kidney. Eur J Pediatr 1998; 157(4):287-290

31 Usuki N, Miyamoto T. A case of congenital absence of the intrahepatic portal vein diagnosed by MR angiography. J Comput Assist Tomogr 1998;22(5):728-729

32 Yoon HK, Choo SW, Do YS, Choo IW, Han BK. Congenital intrahepatic portosystemic shunts in the neonate: coil embolization via the umbilical vein. J Vasc Interv Radiol 1998;9(3):509-511

33 Ihara K, Hijii T, Kuromaru R, et al. High-intensity basal ganglia lesions on T1-weighted images in two toddlers with elevated blood manganese with portosystemic shunts. Neuroradiology 1999;41(3):195-198

34 Ikeda S, Sera Y, Yoshida M, et al. Reversibility of hyperintense globus pallidus on T 1-weighted MRI following surgery for a portosystemic shunt in an 8-year-old girl. Pediatr Radiol 1999; 29(6):449-450

35 Ikeda S, Sera Y, Ohshiro H, Uchino S, Uchino T, Endo F. Surgical indications for patients with hyperammonemia. J Pediatr Surg 1999;34(6):1012-1015

36 Kohda E, Saeki M, Nakano M, et al. Congenital absence of the portal vein in a boy. Pediatr Radiol 1999;29(4):235-237
37 Massin M, Verloes A, Jamblin P. Cardiac anomalies associated with congenital absence of the portal vein. Cardiol Young 1999; 9(5):522-525

38 Schwartz YM, Berkowitz D, Lorber A. Transvenous coil embolization of a patent ductus venosus in a 2-month-old child. Pediatrics 1999;103(5 Pt 1):1045-1047

39 Wakamoto H, Manabe K, Kobayashi H, Hayashi M. Subclinical portal-systemic encephalopathy in a child with congenital absence of the portal vein. Brain Dev 1999;21(6):425-428

40 Ikeda S, Sera Y, Yoshida M, et al. Successful coil embolization in an infant with congenital intrahepatic portosystemic shunts. J Pediatr Surg 1999;34(6):1031-1032

41 Broere D, van Gemert WG, Kneepkens CM, et al. A 6-year-old boy with hyperammonaemia: partial $\mathrm{N}$-acetylglutamate synthase deficiency or portosystemic encephalopathy? Eur J Pediatr 2000;159(12):905-907

42 Courtens W, Segers V, Johansson A, Avni FE. Association between Down syndrome and portohepatic shunt. Am J Med Genet 2000;93(2):166-168

43 Grazioli L, Alberti D, Olivetti L, et al. Congenital absence of portal vein with nodular regenerative hyperplasia of the liver. Eur Radiol 2000;10(5):820-825

44 Kamata S, Kitayama Y, Usui N, et al. Patent ductus venosus with a hypoplastic intrahepatic portal system presenting intrapulmonary shunt: a case treated with banding of the ductus venosus. J Pediatr Surg 2000;35(4):655-657

45 Karashima S, Hattori S, Nakazato H, et al. Membranoproliferative glomerulonephritis in congenital portosystemic shunt without liver cirrhosis. Clin Nephrol 2000;53(3):206-211

$46 \mathrm{Kim}$ IO, Cheon JE, Kim WS, et al. Congenital intrahepatic portohepatic venous shunt: treatment with coil embolisation. Pediatr Radiol 2000;30(5):336-338

47 Shinkai M, Ohhama Y, Nishi T, et al. Living related partial liver transplantation for hyperammonemia due to congenital absence of the portal vein. Transplant Proc 2000;32(7):2184

48 Valls E, Ceres L, Urbaneja A, Muñoz R, Alonso I. Color Doppler sonography in the diagnosis of neonatal intrahepatic portosystemic shunts. J Clin Ultrasound 2000;28(1):42-46

49 Yonemitsu H, Mori H, Kimura T, et al. Congenital extrahepatic portocaval shunt associated with hepatic hyperplastic nodules in a patient with Dubin-Johnson syndrome. Abdom Imaging 2000; 25(6):572-575

50 Kinjo T, Aoki H, Sunagawa H, Kinjo S, Muto Y. Congenital absence of the portal vein associated with focal nodular hyperplasia of the liver and congenital choledochal cyst: a case report. J Pediatr Surg 2001;36(4):622-625

51 Marx M, Huber WD, Crone J, et al. Interventional stent implantation in a child with patent ductus venosus and pulmonary hypertension. Eur J Pediatr 2001;160(8):501-504

52 Satoh M, Yokoya S, Hachiya Y, et al. Two hyperandrogenic adolescent girls with congenital portosystemic shunt. Eur J Pediatr 2001;160(5):307-311

53 Scheer I, Kivelitz D, Taupitz M, et al. Patent ductus venosus: diagnosis by MR angiography. Pediatr Radiol 2001;31(4): 279-282

54 Shinkai M, Ohhama Y, Nishi T, et al. Congenital absence of the portal vein and role of liver transplantation in children. J Pediatr Surg 2001;36(7):1026-1031

55 Venkat-Raman N, Murphy KW, Ghaus K, Teoh TG, Higham JM, Carvalho JS. Congenital absence of portal vein in the fetus: a case report. Ultrasound Obstet Gynecol 2001;17(1):71-75

56 Alvarez AE, Ribeiro AF, Hessel G, Baracat J, Ribeiro JD. Abernethy malformation: one of the etiologies of hepatopulmonary syndrome. Pediatr Pulmonol 2002;34(5):391-394

57 Badler R, Price AP, Moy L, Katz DS. Congenital portacaval shunt: CT demonstration. Pediatr Radiol 2002;32(1):28-30 
58 Ersch J, Bänziger O, Braegger C, Arbenz U, Stallmach T. An infant with pulmonary hypertension due to a congenital porto-caval shunt. Eur J Pediatr 2002;161(12):660-662

59 Araki T, Kamada M, Okamoto Y, Arai S, Oba O. Coil embolization of a patent ductus venosus in a 52-day-old girl with congenital heart disease. Ann Thorac Surg 2003;75(1):273-275

60 Kanamori Y, Hashizume K, Kitano Y, Sugiyama M, Motoi T, Tange T. Congenital extrahepatic portocaval shunt (Abernethy type 2), huge liver mass, and patent ductus arteriosus-a case report of its rare clinical presentation in a young girl. J Pediatr Surg 2003; 38(4):E15

61 Murray CP, Yoo SJ, Babyn PS. Congenital extrahepatic portosystemic shunts. Pediatr Radiol 2003;33(9):614-620

62 Pipitone S, Garofalo C, Corsello G, et al. Abnormalities of the umbilico-portal venous system in Down syndrome: a report of two new patients. Am J Med Genet A 2003;120A(4):528-532

63 Pohl A, Jung A, Vielhaber H, et al. Congenital atresia of the portal vein and extrahepatic portocaval shunt associated with benign neonatal hemangiomatosis, congenital adrenal hyperplasia, and atrial septal defect. J Pediatr Surg 2003;38(4):633-634

64 Suga K, Ogasawara N, Matsunaga N, Sugio Y, Shimizu R. Reversed intrapulmonary right-to-left shunt after banding of the patent ductus venosus. Clin Nucl Med 2003;28(10):827-833

65 Tanaka Y, Takayanagi M, Shiratori Y, et al. Congenital absence of portal vein with multiple hyperplastic nodular lesions in the liver. J Gastroenterol 2003;38(3):288-294

66 Alonso J, Sierre S, Lipsich J, Questa H, Faella H, Moguillansky S. Endovascular treatment of congenital portal vein fistulas with the Amplatzer occlusion device. J Vasc Interv Radiol 2004; 15(9):989-993

67 Charre L, Roggen F, Lemaire J, et al. Hematochezia and congenital extrahepatic portocaval shunt with absent portal vein: successful treatment by liver transplantation. Transplantation 2004;78(9): 1404-1406

68 Eroglu Y, Donaldson J, Sorensen LG, et al. Improved neurocognitive function after radiologic closure of congenital portosystemic shunts. J Pediatr Gastroenterol Nutr 2004;39(4):410-417

69 Kakuno Y, Matsuki M, Kani H, Narabayashi I, Katayama H. Intrahepatic portosystemic venous shunt: occurrence in a child patient without liver cirrhosis. Radiat Med 2004;22(3):195-197

70 Kim T, Murakami T, Sugihara E, Hori M, Wakasa K, Nakamura H. Hepatic nodular lesions associated with abnormal development of the portal vein. AJR Am J Roentgenol 2004;183(5):1333-1338

71 Kimura T, Soh H, Hasegawa T, et al. Laparoscopic correction of congenital portosystemic shunt in children. Surg Laparosc Endosc Percutan Tech 2004;14(5):285-288

72 Kinane TB, Westra SJ. Case records of the Massachusetts General Hospital. Weekly clinicopathological exercises. Case 31-2004. A four-year-old boy with hypoxemia. N Engl J Med 2004;351(16): 1667-1675

73 Manning N, Impey L, Lindsell D, Lakhoo K. Prenatally diagnosed portocaval shunt and postnatal outcome: a case report. Prenat Diagn 2004;24(7):537-540

74 Saxena AK, Sodhi KS, Arora J, Thapa BR, Suri S. Congenital intrahepatic portosystemic venous shunt in an infant with Down syndrome. AJR Am J Roentgenol 2004;183(6):1783-1784

75 Takagaki K, Kodaira M, Kuriyama S, et al. Congenital absence of the portal vein complicating hepatic tumors. Intern Med 2004; 43(3):194-198

76 Takehara Y, Mori K, Edagawa T, et al. Presumed hypoplastic intrahepatic portal system due to patent ductus venosus: importance of direct occlusion test of ductus venosus under open laparotomy. Pediatr Int 2004;46(4):484-486

77 Yoshimoto Y, Shimizu R, Saeki T, et al. Patent ductus venosus in children: a case report and review of the literature. J Pediatr Surg 2004;39(1):E1-E5

78 Yagi H, Takada Y, Fujimoto Y, et al. Successful surgical ligation under intraoperative portal vein pressure monitoring of a large portosystemic shunt presenting as an intrapulmonary shunt: report of a case. Surg Today 2004;34(12):1049-1052

79 Cheung KM, Lee CY, Wong CT, Chan AK. Congenital absence of portal vein presenting as hepatopulmonary syndrome. J Paediatr Child Health 2005;41(1-2):72-75

80 Digilio MC, Capolino R, Marino B, Sarkozy A, Dallapiccola B. Congenital intrahepatic portosystemic venous shunt: an unusual feature in LEOPARD syndrome and in neurofibromatosis type 1. Am J Med Genet A 2005;134(4):457-458

81 Ikeda H, Aotsuka H, Nakajima H, Sawada M. Portosystemic shunt with polysplenia and hypoplastic left heart syndrome. Pediatr Cardiol 2005;26(4):446-448

82 Ohnishi Y, Ueda M, Doi H, et al. Successful liver transplantation for congenital absence of the portal vein complicated by intrapulmonary shunt and brain abscess. J Pediatr Surg 2005;40(5):e1-e3

83 Tsuji K, Naoki K, Tachiyama Y, et al. A case of congenital absence of the portal vein. Hepatol Res 2005;31(1):43-47

84 Gillespie MJ, Golden A, Sivarajan VB, Rome JJ. Transcatheter closure of patent ductus venosus with the Amplatzer vascular plug in twin brothers. Pediatr Cardiol 2006;27(1):142-145

85 Noe JA, Pittman HC, Burton EM. Congenital absence of the portal vein in a child with Turner syndrome. Pediatr Radiol 2006; 36(6):566-568

86 Soejima Y, Taguchi T, Ogita K, et al. Auxiliary partial orthotopic living donor liver transplantation for a child with congenital absence of the portal vein. Liver Transpl 2006;12(5):845-849

87 Sumida W, Kaneko K, Ogura Y, et al. Living donor liver transplantation for congenital absence of the portal vein in a child with cardiac failure. J Pediatr Surg 2006;41(11):e9-e12

88 Tercier S, Delarue A, Rouault F, Roman C, Bréaud J, Petit P. Congenital portocaval fistula associated with hepatopulmonary syndrome: ligation vs liver transplantation. J Pediatr Surg 2006; 41(2):e1-e3

89 Turkbey B, Karcaaltincaba M, Demir H, Akcoren Z, Yuce A, Haliloglu M. Multiple hyperplastic nodules in the liver with congenital absence of portal vein: MRI findings. Pediatr Radiol 2006;36(5):445-448

90 Emre S, Arnon R, Cohen E, Morotti RA, Vaysman D, Shneider BL. Resolution of hepatopulmonary syndrome after auxiliary partial orthotopic liver transplantation in Abernethy malformation. A case report. Liver Transpl 2007;13(12):1662-1668

91 Goo HW. Extrahepatic portosystemic shunt in congenital absence of the portal vein depicted by time-resolved contrast-enhanced MR angiography. Pediatr Radiol 2007;37(7):706-709

92 Kandpal H, Sharma R, Arora NK, Gupta SD. Congenital extrahepatic portosystemic venous shunt: imaging features. Singapore Med J 2007;48(9):e258-e261

93 Kawano S, Hasegawa S, Urushihara N, et al. Hepatoblastoma with congenital absence of the portal vein - a case report. Eur J Pediatr Surg 2007;17(4):292-294

94 Peretta P, Carlino C, Gennari F, et al. Spontaneous occlusion of brainstem arteriovenous malformation following ligature of a hepatic patent ductus venosus. Case report and review of the literature. J Neurosurg 2007;106(2, Suppl):147-152

95 Ratnasamy C, Kurbegov A, Swaminathan S. Cardiac anomalies in the setting of the Abernethy malformation of the portal vein. Cardiol Young 2007;17(2):212-214

96 Sagiv-Friedgut K, Witzling M, Dalal I, Vinkler C, Someh E, Levine A. Congenital patent ductus venosus: an association with the hyper IgE syndrome. J Pediatr 2007;150(2):210-212

97 Yamagami T, Yoshimatsu R, Matsumoto T, et al. Successful embolization using interlocking detachable coils for a congenital extrahepatic portosystemic venous shunt in a child. J Pediatr Surg 2007;42(11):1949-1952

98 Chiu SN, Chien YH, Wu MH, Wang JK, Chen SJ. Transcatheter closure of portal-systemic shunt combining congenital double extrahepatic inferior vena cava with vascular plug. J Pediatr 2008;153(5):723 
99 Hoover W, Ackerman V, Schamberger M, Kumar M, Marshalleck F, Hoyer M. The congenital porto-caval fistula: a unique presentation and novel intervention. Pediatr Pulmonol 2008;43(2): 196-199

100 Morikawa N, Honna T, Kuroda T, et al. Resolution of hepatopulmonary syndrome after ligation of a portosystemic shunt in a pediatric patient with an Abernethy malformation. J Pediatr Surg 2008;43(2):e35-e38

101 Ohno T, Muneuchi J, Ihara K, et al. Pulmonary hypertension in patients with congenital portosystemic venous shunt: a previously unrecognized association. Pediatrics 2008;121(4): e892-e899

102 Singhal M, Lal A, Thapa BR, Prakash M, Shanbhogue KP, Khandelwal N. Congenital atresia of portal vein with portocaval shunt associated with cardiac defects, skeletal deformities, and skin lesions in a boy. J Pediatr Surg 2008;43(8):e25-e28

103 Stringer MD. The clinical anatomy of congenital portosystemic venous shunts. Clin Anat 2008;21(2):147-157

104 Elias N, Scirica CV, Hertl M. Liver transplantation for the Abernathy malformation. N Engl J Med 2008;358(8):858

105 Alomari AI, Chaudry G, Fox VL, Fishman SJ, Buchmiller TL. Atypical manifestation of patent ductus venosus in a child: intervening against a paradoxical presentation. J Vasc Interv Radiol 2009;20(4):537-542

106 Cho YK, Chang NK, Ma JS. Successful transcatheter closure of a large patent ductus venosus with the Amplatzer vascular plug II. Pediatr Cardiol 2009;30(4):540-542

107 Evans WN, Galindo A, Acherman RJ, Rothman A, Berthoty DP. Congenital portosystemic shunts and AMPLATZER vascular plug occlusion in newborns. Pediatr Cardiol 2009;30(8):1083-1088

108 Gupta V, Kalra N, Vyas S, Sodhi KS, Thapa BR, Khandelwal N. Embolization of congenital intrahepatic porto-systemic shunt by n-butyl cyanoacrylate. Indian J Pediatr 2009;76(10):1059-1060

109 Hino T, Hayashida A, Okahashi N, et al. Portopulmonary hypertension associated with congenital absence of the portal vein treated with bosentan. Intern Med 2009;48(8):597-600

110 Iida T, Ogura Y, Doi H, et al. Successful treatment of pulmonary hypertension secondary to congenital extrahepatic portocaval shunts (Abernethy type 2) by living donor liver transplantation after surgical shunt ligation. Transpl Int 2010;23(1):105-109

111 Kasahara M, Nakagawa A, Sakamoto S, et al. Living donor liver transplantation for congenital absence of the portal vein with situs inversus. Liver Transpl 2009;15(11):1641-1643

112 Kono T, Hiki T, Kuwashima S, Hashimoto T, Kaji Y. Hypergalactosemia in early infancy: diagnostic strategy with an emphasis on imaging. Pediatr Int 2009;51(2):276-282

113 Nii A, Takehara HO, Kuyama H, Shimada M. Successful preemptive surgical division of type 2-congenital extrahepatic portosystemic shunt in children. J Med Invest 2009;56(1-2):49-54

114 Peker A, Ucar T, Kuloglu Z, Ceyhan K, Tutar E, Fitoz S. Congenital absence of portal vein associated with nodular regenerative hyperplasia of the liver and pulmonary hypertension. Clin Imaging 2009;33(4):322-325

115 Singhal A, Srivastava A, Goyal N, et al. Successful living donor liver transplant in a child with Abernethy malformation with biliary atresia, ventricular septal defect and intrapulmonary shunting. Pediatr Transplant 2009;13(8):1041-1047

116 Sista AK, Filly RA. Type 1 congenital extrahepatic portosystemic shunt. J Ultrasound Med 2009;28(5):703-705

117 Tsutsui M, Sugahara S, Motosuneya T, et al. Anesthetic management of a child with Costello syndrome complicated by congenital absence of the portal vein-a case report. Paediatr Anaesth 2009;19(7):714-715

118 Franchi-Abella S, Branchereau S, Lambert V, et al. Complications of congenital portosystemic shunts in children: therapeutic options and outcomes. J Pediatr Gastroenterol Nutr 2010; 51(3):322-330
119 Ferrero GB, Porta F, Biamino E, et al. Remittent hyperammonemia in congenital portosystemic shunt. Eur J Pediatr 2010;169 (3):369-372

120 Fuchs J, Warmann SW, Sieverding L, et al. Impact of virtual imaging procedures on treatment strategies in children with hepatic vascular malformations. J Pediatr Gastroenterol Nutr 2010;50(1):67-73

121 Kamimatsuse A, Onitake Y, Kamei N, et al. Surgical intervention for patent ductus venosus. Pediatr Surg Int 2010;26(10): $1025-1030$

122 Koga H, Miyako K, Sakemi Y, Hidaka T, Suga N, Takahashi N. Congenital portosystemic shunt in a child with Wolf-Hirschhorn syndrome. Am J Med Genet A 2010;152A(9):2387-2389

123 Kuo MD, Miller FJ, Lavine JE, Peterson M, Finch M. Exploiting phenotypic plasticity for the treatment of hepatopulmonary shunting in Abernethy malformation. J Vasc Interv Radiol 2010;21(6):917-922

124 Lee SA, Lee YS, Lee KS, Jeon GS. Congenital intrahepatic portosystemic venous shunt and liver mass in a child patient: successful endovascular treatment with an Amplatzer vascular plug (AVP). Korean J Radiol 2010;11(5):583-586

125 Matsuura T, Soejima Y, Taguchi T. Auxiliary partial orthotopic living donor liver transplantation with a small-for-size graft for congenital absence of the portal vein. Liver Transpl 2010; 16(12):1437-1439

126 Nagasaka H, Okano Y, Aizawa M, et al. Altered metabolisms of mediators controlling vascular function and enhanced oxidative stress in asymptomatic children with congenital portosystemic venous shunt. Metabolism 2010;59(1):107-113

127 Newman B, Feinstein JA, Cohen RA, et al. Congenital extrahepatic portosystemic shunt associated with heterotaxy and polysplenia. Pediatr Radiol 2010;40(7):1222-1230

128 Osorio MJ, Bonow A, Bond GJ, et al. Abernethy malformation complicated by hepatopulmonary syndrome and a liver mass successfully treated by liver transplantation. Pediatr Transplant 2011;15(7):E149-E151

129 Hori T, Yonekawa Y, Okamoto S, et al. Pediatric orthotopic livingdonor liver transplantation cures pulmonary hypertension caused by Abernethy malformation type Ib. Pediatr Transplant 2011;15(3):e47-e52

130 Kobayashi D, Edwards HD, Singh J, Nadkarni MD, Lantz PE, Cook AL. Portopulmonary hypertension secondary to congenital extrahepatic portosystemic shunt with heterotaxy and polysplenia: a cause of sudden death in an infant. Pediatr Pulmonol 2011;46 (10):1041-1044

131 Konstas AA, Digumarthy SR, Avery LL, et al. Congenital portosystemic shunts: imaging findings and clinical presentations in 11 patients. Eur J Radiol 2011;80(2):175-181

132 Lautz TB, Tantemsapya N, Rowell E, Superina RA. Management and classification of type II congenital portosystemic shunts. J Pediatr Surg 2011;46(2):308-314

133 Law YM, Mack CL, Sokol RJ, Rice M, Parsley L, Ivy D. Cardiopulmonary manifestations of portovenous shunts from congenital absence of the portal vein: pulmonary hypertension and pulmonary vascular dilatation. Pediatr Transplant 2011;15(8): E162-E168

134 Sakamoto S, Kasahara M, Shigeta T, et al. Living donor liver transplantation for multiple intrahepatic portosystemic shunts after involution of infantile hepatic hemangiomas. J Pediatr Surg 2011;46(6):1288-1291

135 Sanada Y, Urahashi T, Ihara Y, et al. The role of operative intervention in management of congenital extrahepatic portosystemic shunt. Surgery 2012;151(3):404-411

136 Stewart JK, Kuo WT, Hovsepian DM, Hofmann LV, Bonham CA, Sze DY. Portal venous remodeling after endovascular reduction of pediatric autogenous portosystemic shunts. J Vasc Interv Radiol 2011;22(8):1199-1205 
137 Grimaldi C, Monti L, Falappa P, d'Ambrosio G, Manca A, de Ville de Goyet J. Congenital intrahepatic portohepatic shunt managed by interventional radiologic occlusion: a case report and literature review. J Pediatr Surg 2012;47(2):e27-e31

$138 \mathrm{Kim} \mathrm{MJ}$, Ko JS, Seo JK, et al. Clinical features of congenital portosystemic shunt in children. Eur J Pediatr 2012;171(2): 395-400

139 Nakamura Y, Aoki M, Hagino I, Nakajima H. Severe cyanosis after Kawashima operation resulting from congenital portosystemic shunt. Ann Thorac Surg 2012;93(4):1315-1317

140 Passalacqua M, Lie KT, Yarmohammadi H. Congenital extrahepatic portosystemic shunt (Abernethy malformation) treated endovascularly with vascular plug shunt closure. Pediatr Surg Int 2012;28(1):79-83

141 Park JH, Cha SH, Han JK, Han MC. Intrahepatic portosystemic venous shunt. AJR Am J Roentgenol 1990;155(3):527-528

142 Lisovsky M, Konstas AA, Misdraji J. Congenital extrahepatic portosystemic shunts (Abernethy malformation): a histopathologic evaluation. Am J Surg Pathol 2011;35(9):1381-1390

143 Bioulac-Sage P, Saric J, Boussarie L, Balabaud C. Congenital portacaval shunt in rats: liver adaptation to lack of portal vein-a light and electron microscopic study. Hepatology 1985;5(6):1183-1189

144 Gitzelmann R, Forster I, Willi UV. Hypergalactosaemia in a newborn: self-limiting intrahepatic portosystemic venous shunt. Eur J Pediatr 1997;156(9):719-722

145 Ono H, Mawatari H, Mizoguchi N, Eguchi T, Sakura N. Clinical features and outcome of eight infants with intrahepatic portovenous shunts detected in neonatal screening for galactosaemia. Acta Paediatr 1998;87(6):631-634

146 McElhinney DB, Marx GR, Newburger JW. Congenital portosystemic venous connections and other abdominal venous abnormalities in patients with polysplenia and functionally univentricular heart disease: a case series and literature review. Congenit Heart Dis 2011;6(1):28-40

147 Acherman RJ, Evans WN, Galindo A, et al. Diagnosis of absent ductus venosus in a population referred for fetal echocardiography: association with a persistent portosystemic shunt requiring postnatal device occlusion. J Ultrasound Med 2007;26(8):1077-1082

148 Contratti G, Banzi C, Ghi T, Perolo A, Pilu G, Visentin A. Absence of the ductus venosus: report of 10 new cases and review of the literature. Ultrasound Obstet Gynecol 2001;18(6):605-609
149 Shen O, Valsky DV, Messing B, Cohen SM, Lipschuetz M, Yagel S. Shunt diameter in agenesis of the ductus venosus with extrahepatic portosystemic shunt impacts on prognosis. Ultrasound Obstet Gynecol 2011;37(2):184-190

150 Shiomi S, Kuroki T, Kurai O, et al. Portal circulation by technetium-99m pertechnetate per-rectal portal scintigraphy. J Nucl Med 1988;29(4):460-465

151 Inoue E, Hori S, Narumi Y, et al. Portal-systemic encephalopathy: presence of basal ganglia lesions with high signal intensity on MR images. Radiology 1991;179(2):551-555

152 Krieger S, Jauss M, Jansen O, et al. MRI findings in chronic hepatic encephalopathy depend on portosystemic shunt: results of a controlled prospective clinical investigation. J Hepatol 1997; 27(1):121-126

153 Uchino A, Noguchi T, Nomiyama K, et al. Manganese accumulation in the brain: MR imaging. Neuroradiology 2007;49(9): 715-720

154 Mizoguchi N, Nishimura Y, Ono H, Sakura N. Manganese elevations in blood of children with congenital portosystemic shunts. Eur J Pediatr 2001;160(4):247-250

155 Uchino T, Matsuda I, Endo F. The long-term prognosis of congenital portosystemic venous shunt. J Pediatr 1999;135(2 Pt 1): 254-256

156 Raskin NH, Price JB, Fishman RA. Portal-systemic encephalopathy due to congenital intrahepatic shunts. N Engl J Med 1964; 270:225-229

157 Spencer LT, Langham MR, Hoyer MH, Jones DA, Caridi JG, Chesrown SE. Resolution of hypoxemia in a liver transplant recipient after ligation of a portosystemic shunt. J Pediatr 2000;137(4):575-577

158 Hervé P, Le Pavec J, Sztrymf B, Decante B, Savale L, Sitbon O. Pulmonary vascular abnormalities in cirrhosis. Best Pract Res Clin Gastroenterol 2007;21(1):141-159

159 Weinbren K, Washington SL. Hyperplastic nodules after portacaval anastomosis in rats. Nature 1976;264(5585): 440-442

160 Braissant O. Ammonia toxicity to the brain: effects on creatine metabolism and transport and protective roles of creatine. Mol Genet Metab 2010;100(Suppl 1):S53-S58

161 Racette BA, Aschner M, Guilarte TR, Dydak U, Criswell SR, Zheng W. Pathophysiology of manganese-associated neurotoxicity. Neurotoxicology 2012;33(4):881-886 